\title{
SOCIALIZAÇÃO DA DISCIPLINA TÓPICOS ESPECIAIS EM EDUCAÇÃO: Um breve estudo sobre categorias numa perspectiva sócio-histórica
}

\author{
Socialization of discipline special topics in education: a brief study on categories from \\ a socio-historical perspective
}

Smael Maicon de Sousa Lima ${ }^{1}$

Carmen Lúcia de Oliveira Cabral ${ }^{2}$

\begin{abstract}
RESUMO: O presente artigo pretende fazer uma discussão teórica, e, sobretudo, uma discussão reflexiva sobre algumas categorias propostas pela Psicologia SócioHistórica, a qual tem como autor central, Vygotsky (2009). Abordamos, as categorias do método materialista histórico e dialético proposto por Karl Marx. Com esse intuito daremos ênfase em categorias: Atividade, Consciência, Sentido e Significado e Pensamento e Linguagem, as quais possibilitam uma compreensão acerca do objeto de estudo de nossa discussão, a saber: a formação dos professores de língua francesa da Universidade Federal do Piauí (UFPI), visto que a mesma configura-se como uma das grandes possibilidades de formação continuada muito utilizada pelos professores que têm compromisso político social com suas profissões e com a academia. A apropriação desse conhecimento é essencial para entendermos as mediações sociais pelas quais passamos desde o nascimento até a nossa morte, e como elas interferem no processo de formação humana e docente, neste caso.
\end{abstract}

Palavras-chave: Categorias. Reflexão. Psicologia Sócio-Histórica.

ABSTRACT: The present article intends to make a theoretical discussion, and, above all, a reflexive discussion about some categories proposed by Socio-Historical Psychology, which has as central author, Vygotsky. We address the categories of historical and dialectical materialist method proposed by Karl Marx. With this in mind, we will emphasize the following categories: Activity, Consciousness, Meaning and Meaning and Thought and Language, which allow an understanding about the subject of our discussion, namely: the training of French-speaking teachers of the Federal University of Piauí (UFPI), since it is one of the great possibilities for continuing education that is widely used by teachers who have a social and political commitment to their professions and to the academy. The appropriation of this knowledge is essential for understanding the social mediations through which we passed from birth until our death, and how they interfere in the process of human and teacher formation in this case.

\footnotetext{
${ }^{1}$ Graduado em Letras - Português/Francês (UFPI). Mestre em Educação (UFPI). E-mail: smael.prof.de.frances@gmail.com

${ }^{2}$ Doutora em Educação (UFRN). Professora Associada IV da Universidade Federal do Piauí, atuando na graduação em Pedagogia e no Programa de Pós-Graduação em Educação (PPGED). E-mail: carmensafira@bol.com.br
} 
Keywords: Categories. Reflection. Socio-Historical Psychology.

\section{ENTENDENDO A PROPOSTA DO ARTIGO EM ELEMENTOS INTRODUTÓRIOS}

A título de elementos introdutórios é importante direcionar o leitor no que tange ao que será exposto no estudo, de modo sequencial. Este artigo está dividido em três partes, no primeiro momento fazemos uma apresentação geral do que é exposto neste trabalho, mencionando a teoria que embasa o estudo; no segundo momento, teremos uma discussão de literatura, ou seja, argumentações teóricas sobre a psicologia sócio-histórica; e, no terceiro momento, teremos uma reflexão de abstrações construídas durante o estudo, de acordo com a socialização feita em sala de aula, após leituras indicadas; e, por fim, as considerações abertas.

Para tanto, vale dizer que este artigo é resultado da disciplina "Tópicos Especiais em Educação", oferecida no curso de Mestrado em Educação do Programa de Pós-graduação em Educação (PPGED) da Universidade Federal do Piauí (UFPI) ${ }^{3}$. A disciplina teve o objetivo fazer um estudo prospectivo sobre a psicologia sócio-histórica, bem como, entender o que preconiza o método materialista histórico-dialético. Tivemos como foco, enveredar por algumas categorias centrais que são pertinentes e essenciais para o entendimento das demais categorias.

De acordo com o parágrafo anterior, faz-se necessário mencionar especificamente, as categorias que foram mais evidenciadas, sendo elas: Atividade, Consciência, Significado e Sentido, Pensamento e Linguagem. O entendimento sobre as mesmas permitiu-se que pudéssemos fazer relações com objetos de estudo de pesquisas científicas em Educação.

Além disso, o presente texto tem a intenção de compartilhar o que foi aprendido, o que foi pensado e a que conclusões chegamos dentro de uma perspectiva social e histórica para apreciação de demais leitores que pretendem enveredar por este caminho de pesquisa, ou seja, de pré-pesquisadores que se

\footnotetext{
${ }^{3}$ A disciplina e as socializações que geraram este estudo foram construídas sob a mediação da professora Dra. Eliana Alencar, professora do PPGED/UFPI e grande estudiosa da área.
}

Cadernos Cajuína, V. 4, N. 1, 2019, p. 105 - 118.

ISSN: 2448-0916 
interessam pela psicologia sócio-histórica, proposta por Vygotsky, bem como, seguir o método materialista histórico e dialético.

Portanto, entender as categorias acima mencionadas é enxergar o que se pretende estudar numa pesquisa cientifica dessa área. O objeto de pesquisa que se pretende produzir, através de dados, como por exemplo, a interpretação de entrevistas narrativas, como instrumento de pesquisa e analisar como se constituem os Sentidos e Significados na formação do professor de francês da UFPI, bem como relacionar com a prática desenvolvida na realidade social da profissão.

Para isso é necessário permear por leituras que dão o esclarecimento de outras categorias centrais como a Atividade, a Consciência, o Significado e Sentido e Linguagem e pensamento. A atividade é uma categoria primordial para o entendimento das demais. Ela é uma categoria que proporciona o movimento do homem, enquanto ser ontológico; a Consciência é na verdade o reconhecimento de si, é chegar no entendimento de que somos aquilo que construímos ao longo da vida, com historicidade e, consequente, apreensão de signos sociais e linguísticos.

Já o Sentido é aquilo que temos como relevante para cada indivíduo dentro de sua singularidade, no que podemos dizer microgênese; o significado é o que pensamos imediatamente, quando fazemos relação do objeto com o que ele representa. Pensamento e Linguagem são categorias díspares, no entanto, se compreendem, considerando-se que, o pensamento precede a linguagem. No decorrer no texto, teremos um maior esclarecimento no que tange as próprias categorias ditas aqui, bem como, a base de seus estudos na sessão seguinte.

\section{FORMAÇÃo DE PROFESSORES: UMA TENTATIVA DE JUSTIFICAR O ESTUDO}

Estudar a formação do professor em meio a diversos acontecimentos pelos quais perpassam o mundo é compreender melhor sobre a reflexão da própria formação e subentender as implicações dessa formação na prática.

Reflexão e educação são termos que suscitam o sentido de transformação, pois são características de indivíduos capazes de pensar. Pensar é existir, é ser gente, é viver num mundo real, é ter uma relação com esse mundo e interagir com ele. "Essa relação homem-realidade, homem-mundo, [...] implica a transformação do mundo..." (FREIRE, 1979, p. 17). 
Baseado no autor supramencionado, entende-se que estudar a formação do professor e a realidade social pela qual passa o Brasil é contribuir significativamente com este processo de infinitos caminhos. Freire (1979), ao falar sobre viver no "mundo real" é o que faz referência a Vygotsky (2009) em sua psicologia social, quando o autor russo também contribui com o pensamento de que as relações do homem com o mundo são suscetíveis a transformações no processo de formação, e, sobretudo, no processo educacional, através de uma dialética.

Estudar a formação do professor de francês é o que, neste momento, me faz pensar melhor sobre a minha própria formação. Essa pesquisa nasce de muitas inquietações sobre o ser professor de francês na UFPI, por conta de haver poucos trabalhos nessa área no âmbito da educação, além disso, estudar a formação do professor de língua estrangeira é adentrar num mundo de significados e sentidos. $O$ mundo cada vez mais está sendo intercultural e internacional, e, porque não dizer, permeado por diversas conexões culturais, sociais e históricas.

A psicologia social dará esclarecimentos sobre o processo de formação com teorias de Vygotsky (2009). Na área da educação, os profissionais do ensino são dirigidos e (auto)dirigidos pelos mesmos fatores relacionados às atitudes e perspectivas que consistem numa busca de reposição e atualização dos conhecimentos, de modo a construir e reconstruir competências antigas e novas competências profissionais, exigidas pelos contextos acadêmicos cientifico e do mercado de trabalho.

$\mathrm{Na}$ área do ensino de língua francesa, a importância desses processos de estudar a formação à luz do método materialista e materialista dialético, bem como, teorizar sobre a psicologia social, revela-se igualmente importante, a fim de entender como está sendo construída a formação desse profissional na modernidade, posto que apenas a graduação na referida área e uma pós-graduação não são suficientes para consolidar os conhecimentos de que um professor de língua francesa necessita para exercer a sua profissão durante toda sua trajetória docente. Isto porque, os conhecimentos linguísticos de todos os idiomas estão em permanentes mudanças, além disso, o que se estuda numa graduação ou pós-graduação corresponde apenas aos saberes linguísticos e literários de um idioma no momento da aprendizagem adquirida pelo aluno profissional. 
Outro fator de suma importância para a busca de conhecimentos sobre formação dos professores de língua francesa está relacionado aos limites ou lacunas deixadas dentro da formação por estes profissionais, uma vez que eles não conseguem desenvolver todas as habilidades linguísticas e literárias da língua francesa, suficientes e necessárias para o exercício pleno da docência com a qualidade exigida pelos diferentes contextos profissionais do mercado de trabalho na referida área.

Neste sentido, entendemos a necessidade de estudar a psicologia sóciohistórica, a fim de que possamos compreender melhor sobre a formação dos professores de língua francesa, visto que a mesma configura-se como uma das grandes possibilidades de formação continuada muito utilizada pelos professores que têm compromisso político social com suas profissões e com a academia. Porém, no âmbito da UFPI pouco se sabe sobre a formação do professor da área em questão.

Além disso, é de fundamental importância que tenhamos a preocupação de estudar a pessoa do professor, com o propósito de compreender esse profissional, e, fomentar que os educadores, de um modo geral, possam entender a si próprios, sua formação e sua prática, pois esses períodos de mudanças tecnológicas, políticas, de globalização, dentre outras, precisam ser acompanhadas e utilizadas de modo a não prejudicar a formação do professor.

No contexto social atual, vemos que o Brasil está na categoria de um país emergente e uma das soluções para o seu avanço e desenvolvimento é, sem dúvida, a educação, a responsável pela mudança que o país carece. Estudar a formação do professor é investigar a prática docente, e, por meio da pesquisa, trazer à luz das teorias, alternativas, mudanças, ou mesmo, apontar e aprofundar debates sobre a formação docente, no concernente, neste caso, específico, sua formação histórico-social. A formação do professor de francês é permeada por diversos instrumentos dos signos linguísticos.

Para tanto, podemos entender que dialética, hibridez, conexão, pensamento crítico só se tornam possíveis com o domínio da linguagem, tendo em vista que, tudo é linguagem e que ela acontece nas interações sociais, com o mundo. Segundo Vygotsky (2009), o desenvolvimento não está desligado do contexto social, histórico e cultural. O desenvolvimento do ser humano é mediado pelos instrumentos dos signos linguísticos. 
As contribuições para o estudo deste tema têm como maior objetivo esclarecer a formação do professor de francês da UFPI, numa perspectiva vygostkiana, ou seja, através de uma abordagem social, cultural, histórica, oferecendo, por meio das narrativas de diferentes professores da UFPI, possíveis compreensões sobre a constituição dos sentidos e significados na formação do professor de francês e a sua relação com a prática, sobretudo, a formação em si.

\section{CONHECENDO A PSICOLOGIA SÓCIO-HISTÓRICA E ENTENDENDO O SEU MÉTODO}

Esta sessão traz a discussão teórica sobre a elucidação do método, ou seja, o que podemos chamar de materialismo histórico-dialético, proposto por Karl Marx no qual serve de guia e suporte de argumentação para o estudo e entendimento da Psicologia Sócio-Histórica em Vygotsky.

Partido disso, entender o método materialista de Karl Marx é perpassar por um estudo sobre como esse método se desenvolveu a partir de contradições que serviram para a confirmação do estudo da dialética marxiana, pensando sobre a concepção e entendimento da superação da luta de classes, algo que é de extrema profundidade, e que constitui a base para os preceitos preconizados pela Psicologia Sócio-História, ou, Psicologia histórico Social.

E no que tange a perspectiva desta proposta, pretende-se entender as categorias da Psicologia já mencionadas, pois é através delas, que, de certa forma, o ser social, o professor, o médico, o engenheiro, a dona de casa e dentre outros se tornam homens sociais e culturais, por meio de uma categoria de exemplo ao entendimento de muitos que venho dizer, a linguagem. Para entender a formação numa perspectiva histórico-social é importante adentrar no estudo dos atos psicológicos da consciência.

O que será exposto do decorrer dessa fase de escrita é a relação do objeto de pesquisa atrelado a essa gama teórica acerca do método e da própria Psicologia Social, compreendendo, em evidência as categorias que foram revisitadas: Atividade, Consciência, Pensamento e Linguagem, e, por fim e não menos importante, Significado e Sentido. Para isso e por uma ordem de melhor entendimentos, trazemos uma citação que explica de breve modo o Método Histórico-Dialético, visto em Marx e Engels. 
São os homens que, desenvolvendo sua produção material e suas relações materiais, transformam, com realidade que lhes é própria, seu pensamento e também os produtos do seu pensamento. Não é a consciência que determina a vida, mas sim a vida que determina a consciência. (MARX; ENGELS, 2007, p. 19-20).

Para explanar a citação acima, tomemos como referência o seguinte encadeamento vocabular tese-antítese-síntese, pois, é desse modo que na Ideologia Alemã compreendemos este processo de que o homem ou o indivíduo, dependem de suas condições materiais, os modos de produzir, bem como as suas relações de produção.

Marx, na sua condição de estudioso da sociedade burguesa, estudou sobre a classe burguesa e analisou os impactos ou as ocorrências que sucederam com relação a luta de classes naquele período, a fim de detectar se o ser humano é dependente de suas relações de produção e envereda-se para o trabalho, o que gera a economia e o que move as pessoas para estarem aptas para as demais atividades que são desenvolvidas numa sociedade.

Além disso, pode-se mencionar que o materialismo de Marx nasce de uma relação com a dialética de Hegel, a qual estava ligada ao plano ideal, onde concebiam um deus para transformar o homem; logo mais, a crítica de Feurbach sobre concepções religiosas apresenta-se de modo diferenciado, não se trata mais de uma religião ou um deus específico, mas de uma religião dos homens. "Feurbach converte a essência religiosa em essência humana. Mas a essência do homem não é uma abstração inerente ao indivíduo isolado. Na sua realidade, ela é um conjunto de relações sociais" (MARX, VI tese).

Entretanto, para Marx o que ainda faltava era sair do plano ainda considerado ideal, partindo do pensamento de lógica não formal, que a religião é uma criação ou um reflexo cultural. Com isso, Marx buscou evidenciar a historicidade como uma categoria propulsora para o entendimento do ser social. Todos os indivíduos são produtos daquilo que foram construindo ao logo do seu processo de vida, inclusive, desde o nascimento.

Em se tratando de criança, é importante agora, ressaltarmos os estudos da psicologia Sócio-Histórica, com a qual é possível entendermos o pensamento, a construção da linguagem e as categorias outras que foram expostas na introdução 
deste artigo. No que concerne a essa teoria, apontamos uma citação que esclarece de modo profícuo e breve a teoria de Vygotsky.

A concepção instrumental de Vygotski estava, pois, indissoluvelmente ligada à ideia de gênese histórico cultural das funções superiores, isto é, da gênese social do indivíduo. Para ele, a consciência e as funções superiores originam-se no espaço exterior, na relação objetiva com os objetos e pessoas, nas condições da vida social [...] Vygotsky chamava de internalização a reconstrução interna da atividade externa. Sem os signos externos, principalmente a linguagem, não seria possível à internalização e a construção das funções superiores. (FREITAS, 1994 apud BOCK, 1999, p. 31)

Quando lemos na citação funções superiores é o momento de esclarecer o que sejam essas tais funções: houve um estudo sobre o desenvolvimento e construção do pensamento, relacionando as funções superiores do homem primitivo, o que conseguiu detectar uma linguagem pré-intelectual nesses homens e, em contrapartida, estudar as funções iniciais da criança, as quais existem muitas similaridades com as funções da criança. Daí, a pretensão de compreender que o que difere o homem social do homem primitivo, que é, justamente, a capacidade que homem tem de ser mediado pela linguagem e, por conseguinte, fazer uso de instrumentos diversos.

\subsection{A compreensão das categorias}

Nesta subseção far-se-á um esclarecimento sequencial de cada categoria que foi estudada na disciplina "Tópicos em Educação". Citaremos grandes nomes que contribuem para o desenvolvimento teórico da psicologia histórico-Social. Temse a pretensão de tornar claro o que são as categorias: Atividade, Consciência, Pensamento e linguagem e Significado e Sentido.

Desde muito tempo é sabido que a filosofia vem tentando compreender o homem em suas mais particulares manifestações de vida. No que tange a isso, podemos falar sobre a filosofia empirista e a filosofia idealista, a primeira está atrelada ao que concerne conhecer o homem através das ciências naturais atendendo a análise de processos mais simples, excluindo a consciência humana (REGO, 1995). Já a segunda perspectiva filosófica, pretende atuar no campo ideal, dos fenômenos onde pode-se pensar que consciência e espírito se relacionam. 
Atualmente, tem-se duas novas formas de compreender 0 homem, buscando enxergar e analisar o desenvolvimento e construção do homem. Podemos ressaltar duas de grande interesse para este artigo, são elas; a teoria de Piaget e a teoria Sócio-Histórica de Vygotsky. A perspectiva de Vygotsky compreende o que se vê na seguinte citação 'há um homem que se atualizará, que se realizará, se as condições adequadas forem dadas' (BOCK, 1997), o que pode-se entender que o homem está se construindo, de acordo com as mediações necessárias para o desenvolvimento da própria vida.

Para adentrar nas categorias é igualmente necessário citar Leontiev (2004) "só se apropriando da herança deixada por seus ancestrais, o homem adquire no decurso de sua vida, as propriedades e faculdades verdadeiramente humanas". Esta citação faz-se compreender também, que ter faculdades humanas é se apropriar também de uma cultura, que esta, por sua vez, só existe através da mediação da linguagem e embora saibamos que o ser humano é biológico, ele só se desenvolve e se constrói enquanto ser social na interação com o outro e falar em interação é falar de ação ou atividade, o que move o homem até chegar no desenvolvimento de uma cultura é a atividade deste indivíduo. As categorias serão expostas sequencialmente, a Atividade, a Consciência, o Pensamento e Linguagem, bem como os Sentidos e Significados.

Para compreender a Atividade traz-se à luz Leontiev (2004) quando diz:

É devido ao fato de a atividade criar um elo prático entre sujeito e mundo circundante agindo sobre ele, e se submeter as prioridades objetivas, que aparecem no sujeito os fenômenos um reflexo do mundo cada vez mais adequado. Na medida em que a atividade é mediatizada por estes fenômenos particulares e o comporta de certa maneira em si, ela torna-se uma atividade mentalizada.

Para tanto, entende-se que é através da atividade humana que torna-se possível a ligação entre o sujeito e as coisas no mundo, como vemos, a relação do sujeito com o objeto, e, esta relação é mediada pela linguagem, e, ao mesmo tempo, pode-se atrelar o que vê-se na citação como atividade mentalizada, pois, é sabido que desde as antigas sociedades o que mantinha ou proporcionava movimentos, ou seja, nas sociedades antigas percebe-se que através do trabalho ainda que fossem para as necessidades mais instintivas como se defender, usar instrumentos, busca por alimentos, para se conseguir algo era necessário o uso da categoria atividade. 
Já entender a consciência, pressupõe adentrar no que estuda Vygotsky (2001), um autor que pode ser citado com bastante veemência, quando diz que a forma mais complexa de organização de nossa conduta, particularmente como um desdobramento da experiência, que permite prever e antecipar os resultados de um dado trabalho nossas próprias condutas no sentido desse resultado.

Portanto, é importante que possa-se relacionar essa complexidade no que concerne fazer relação entre o objetivo e o subjetivo da realidade vivida pelo ser humano, a consciência é uma função psicológica ligada a linguagem interior, ou seja, a linguagem não dita.

Falar da consciência é também adentrar em duas categorias que proporcionam o desenvolvimento da consciência, ou seja, o Pensamento e Linguagem. Como podemos ver a linguagem e o pensamento são categorias diferentes, embora elas se misturem num determinado tempo. Os signos, entendidos como instrumentos convencionais de natureza social, sãos meios de contato com o indivíduo com o mundo exterior e, também, consigo mesmo, com sua própria consciência (AGUIAR et al., 2011).

Nesta citação pode-se ver que os signos representam parcialmente a Linguagem e o Pensamento. A linguagem é um sistema de códigos aceitos em uma sociedade para fins comunicacionais, o que que nos mostra uma certa arbitrariedade, ou seja, são códigos construídos social e culturalmente, de outro lado, vê-se o pensamento como algo de maior profundidade, é algo mais peculiar o indivíduo.

Para fazer parte desta engrenagem traz-se para o momento a explanação do que seja Sentidos e Significados, categorias que leva-nos a compreender melhor sobre Pensamento e Linguagem.

O Sentido e Significado são categorias importantes para compreender o homem e sua consciência, ou seja, o significado como fora exposto anteriormente, diz respeito ao sistema de signos impostos pela sociedade, o que nos faz entender que os significados são produtos do que se constrói historicamente na relação com os pares, na vivência em sociedade. Já os Sentidos são mais profundos, ou seja, os Sentidos são, na verdade, o que o indivíduo internaliza e dá maior importância no que concerne a ser algo mais peculiar e evidente na vida de cada sentido construído por cada um. 
Conforme Oliveira (2002), 'o significado propicia a mediação simbólica entre o indivíduo e o mundo real, constituindo-se no filtro por meio do qual o indivíduo é capaz de compreender o mundo e agir sobre ele', portanto, entende-se que uma vez que em meio a sociedade os seres humanos se apropriam dos significados estes mesmos se reconstroem e a partir daí por uma questão de subjetivação desse significado cada um entre esses indivíduos nascem os respectivos sentidos algo que não se apresenta de imediato como os significados, mas sim para além disso.

Segundo Aguiar et al (2009), 'o sentido se refere à totalidade do sujeito histórico e a sua condição vital', é por isso que entende-se o sentido como algo mais subjetivo que cada ser reconfigura através de seus significados em sentidos individuais, ou seja, o sentido é a parte mais individual que o homem utilizada dessa linguagem significada, o que perpassa pela mediação com os pares, na convivência, nas relações sociais, o uso do significado posto pela sociedade é a partir de então transformado em sentidos para cada um de nós, a exemplo, diríamos que um livro de francês para toda sociedade, uma vez que livro de francês seja entendido por todos é de entendimento generalizado, significado, imediato, agora um livro de francês para um francês ou mesmo para um professor de francês este objeto terá o mesmo significado, entretanto pode ser um outro sentido para este professor, ou para o francês em vista de sabermos que para ambos não é apenas um livro de francês, mas sim uma ferramenta de trabalho ou algo que represente a sua nação.

\section{RELAÇÃO COM O OBJETO DE ESTUDO: UMA PROPOSTA PRELIMINAR PARA A CONSTRUÇÃO DA DISSERTAÇÃO}

Na presente sessão tratar-se-á da relação das categorias apresentadas no que tange ao que foi discutido na disciplina "Tópicos Especiais em Educação", e o que e tem de relativo entre a teoria sobre as categorias com os Sentidos e Significados constituídos na formação do professor de francês da UFPI. Para tanto, é relevante dizer que esta parte será a relação do objeto de pesquisa de mestrado, ou seja, os Sentidos e Significados constituídos na formação do professor de francês na UFPI, o que é estar no campo da Educação bem como detalhar como a teoria sócio-histórica e as categorias que se referem as funções superiores, o que faz a diferença entre as espécies, o homem é um animal que se destaca dentre os outros é entender que este só concretiza essas ditas funções a partir do momento em que 
pode-se adquirir as categorias estudadas, como: a Atividade, a Consciência, o Pensamento e Linguagem, o Sentido e Significado, o que será desenvolvido nos parágrafos subsequentes em relação ao objeto de estudo.

A Atividade se depara da seguinte forma, se o homem é um ser dotado de funções superiores é porque o mesmo desenvolveu e desenvolve uma atividade na terra ou no meio em que ele vive, no que diz respeito a agir sobre o mundo para que se possa exercer alguma atividade sobre ele, a fim de realizar uma necessidade particular. De outro lado, vê-se que a função social e laboral do ser professor é uma atividade desenvolvida por ações que vem de uma certa necessidade, a do trabalho.

Estudar sobre como se constitui os Sentidos e Significados do professor de francês na UFPI é entender como esses profissionais estão agindo ou interferindo no mundo através de sua atividade social e profissional para seus devidos fins.

A Consciência é outra categoria estudada na psicologia sócio-histórica de extrema importância para a proposta de pesquisa pois, é através da consciência que pode-se entender os Sentidos e Significados constituídos por esse professor de francês.

A consciência é, na verdade, a parte mais subjetiva em que pode-se chegar dentro de certos limites. Significa aproximar-se do que seria o Sentido e o Significado dessa formação do professor de francês através de relatos de vida e entrevistas, é interpretar a consciência desse profissional, se aproximar de como ele significa a sua formação, bem como eles dão sentido a ela.

O Pensamento e a Linguagem são categorias chave para se aproximar da consciência do ser humano, uma vez que entende-se que o pensamento precede a palavra torna-se mais claro a compreensão de que a linguagem é um produto criado pelo homem, a fim de configurar uma comunicação profícua e limitada em vista de entender que o pensamento é infinitamente mais profundo do que a linguagem tenta transmitir. Para tanto, estudar o pensamento e a palavra, enquanto categorias influentes para se aproximar da consciência é interpretar numa perspectiva lógica, categorias primeiras que devem ser analisadas e interpretadas antes de se aproximar da consciência, ou seja, para entender ou se aproximar dessa consciência é necessário entender que pensamento e palavra são dois elementos diferentes nesta área de estudo, é, sobretudo, um estudo necessário para entender como são ou como se constituem a formação do professor de francês da UFPI, o 
pensamento e a linguagem são categorias fundamentais para a compreensão do homem social.

E os Sentidos e Significados, significados são na verdade a compreensão e assimilação do sistema de códigos, ou seja, a linguagem adquirida e definida, ou melhor, significada pelo homem durante toda sua história. O significado é a criação de um conceito generalizado, a exemplo, livro, cadeira, mesa, óculos são palavras de significados generalizados que levam a qualquer falante entender como objetos comuns, no entanto durante a produção da realidade essas palavras que foram significados de um modo generalizado pode se reconfigurar com Sentidos diferenciados.

Os sentidos são na verdade aquilo que o homem constrói dentro da sua particularidade, o sentido é algo exponencial, mais prospectivo, ou seja, de encontro ao significado o sentido não é generalizado mas sim particular, é algo intrínseco de cada indivíduo após ter perpassado pelo campo do significado, os sentidos permitem levar a uma zona de sentido, para tanto, relacionando com o objeto de estudo que é a formação do professor de língua estrangeira, é na verdade, tentar penetrar nessa zona de sentido, e, para chegar nesta zona de sentido é necessário perpassar pelas categorias anteriores para ser possível entender o Sentidos e Significados dessa formação do professor de francês através de uma análise de dados baseada em entrevistas autobiografadas por professores de francês desta instituição que fora citada durante todo o trabalho.

\section{CONSIDERAÇÕES ABERTAS}

As considerações abertas são necessárias para que possa reafirmar que no campo científico sempre deve-se estar aberto a refutações, a contradições para que dialeticamente possa-se estabelecer novos movimentos e novas histórias, ideias, pensamentos.

O que podemos concluir acerca deste artigo é que é um estudo atrelado à Ciência da Educação e que envereda pelo caminho teórico da psicologia SócioHistórica, a qual comunga com o Método materialista Histórico e dialético. A psicologia histórico social é capaz de mostrar caminhos jamais vistos sem tais considerações tanto do método quanto da psicologia Sócio-Histórica preconizada por Vygotsky. 
Através do conhecimento de ambas e a apropriação de toda teoria é essencial para entendermos as mediações sociais pelas quais passamos desde 0 nascimento até a nossa morte, é possível, com a contribuição dos fatos psicológicos compreender uma natureza difícil de ser penetrada, ou seja, a linguagem interior desse ser social, que pode ser o professor e demais profissões.

No que tange compreender a constituição dos Sentidos e Significados constituídos na formação do professor de francês da UFPI é chegar próximo de uma zona de sentido, é entender como a relação das categorias estão interligadas e dão acesso a entender como o professor Significa e dá sentido à sua profissão dentro de um viés emocional, ou seja, um viés psicológico do ser humano cultural, histórico e social.

\section{REFERÊNCIAS}

AGUIAR, Wanda Maria Junqueira et al. Reflexões sobre sentido e significado. In: BOCK, Ana Mercês B.; GONÇALVES, Maria da Graça M. (Orgs.). A dimensão subjetiva da realidade: uma leitura sócio-histórica. São Paulo: Cortez, 2009.

AGUIAR, W. M. J.; ROMEU, S. A. Consciência e atividade: categorias fundamentais da psicologia sócio-histórica. In: BOCK, A. M. B.; GONZALEZ, M. G. M.; FURTADO, O. (Orgs.). Psicologia sócio-histórica: uma perspectiva crítica em psicologia. 5. ed. São Paulo: Cortez, 2011.

BOCK, Ana Mercês Bahia. Formação do psicólogo: um debate a partir do significado do fenômeno psicológico. Psicologia, ciência e profissão. vol.17, №. 2 Brasília, p. 37-42, 1997.

MARX, K.; ENGELS, F. A Ideologia Alemã. 3. ed. São Paulo: Martins Fontes, 2007.

FREIRE, Paulo. Educação e mudança. Rio de Janeiro: Paz e Terra, 1979.

LEONTIEV, A. O desenvolvimento do psiquismo. 2. ed. São Paulo: Centauro, 2004.

REGO, T. C. R. Vygotsky: uma perspectiva histórico-cultural da Educação. Petrópolis: Vozes, 1995.

OLIVEIRA, M. K. Vygotsky: aprendizagem e desenvolvimento: um processo sóciohistórico. 4. ed. São Paulo: Scipione, 2002.

VYGOTSKY, L, S. A construção do pensamento e da linguagem. 2. ed. São Paulo: Martins Fontes, 2009. 